dules, as also did the peritoneum of the diaphragm and the pelvis. The pylorus was contracted; and this, with the tumour felt during life, which consisted of a mass of cancerous glands, gave rise to the vomiting.

Herrington Square, London, October, 1858.

\section{CHANCRE IN THE URETHRA MISTAKEN FOR GONORRHOE.}

GRRORS IN THE DIAGXOSIS OF A CHANCRE OF THE THUMB, PRODUCED BY ACCIDENTAL INOCULATION, ASD FOLLOWED BY SECONDARY SYMPTOMS.

By JOSEl'H SAMPSON GAMGEF, Fsq.

In the month of February last, I was requested to see a patient with urethral dischurge, by a friend who had been treating him for about a fortnight, to no purpose, with the ordinary remedies for gonorrhœa.

I found the glans uncovered, red, and swollen; the prepuce cedematous and also red; but their surface was otherwise dry and perfectly healthy. On pressure along the course of the urethra, a small drop of green thick pus appeared at its orifice. The discharge had from the first been very scanty. In the left groin was a lymphatic gland about three times the normal size. The last mentioned symptom, conjoined with the scantiness and viscidity of the discharge, the considerable amount of inflammation about the prepuce, and a knowledge of the fact that gonorrhceal remedies had proved of no use, led me to suspect the existence of chancre within the urethra; accordingly, on opening out its orifice, a small sore with greyish surface and bright red sharply cut edge was visible just within it.

Had the urethral sore healed before it came under my notice, the secondary syphilitic symptoms which would in all probability have succeeded, would have been attributed by the practitioner to gonorrhœa; and this would have added another to the list of badly observed cases invoked by the disciples of Hunter's doctrinc (who hold the virus of syphilis and gonorrhoea to be one and the same) as proof of such identity.

As an additional guarantee of the chancrous nature of the urethral sore, a little of the pus from its surface was inoculated in the thigh, and here a well marked chancre was fully developed about the fourth day.

The primary and inoculated sores were destroyed with nitrate of silver, a mercurial course was prescribed, and the patient was cured within a month.

A few days after I saw this patient, I detected a little fissure at the end of my left thumb, close to the attachment of the nail ; it became exquisitely painful, and sensibly affected the general health. It was only after treating it several days without success, that it occurred to we that in the manouvre necessary to see the urethral chancre (grasping the glans and separating the lips of the meatus with the ends of the thumbs), it was very likely that a little of the virus had got beneath the free margin of the nail, and there produced a chancre.

At this time, the thumb was much swollen; the sore at its end was covered with whitish adherent slough, except at the edge, which was bright red; the lymphatics on the palmar surface of the forearm, and inner surface of the arm, were corded, and their situation was denoted by red lines on the skin. Two friends, who had from the commencement favoured me with their advice, consented to my proposal to inoculate on the arm some of the discharge from the sore, and destroy it with nitric acid; with the double view of arresting the diseased local action, and ascertaining whether it were syphilitic, and mercurial treatment advisable.

The pain and swclling abated very considerably after the cauterisation, and nothing whatever appeared at the two spots on the arm, where the pus had been inoculated. The last fact was deemed proof of the non-syphilitic nature of the disease, and confirmatory of the opinion my friends had from the commencement entertained, that the sore was merely dependent upon rather assiduous applicationd and consequent impairment of health.

When the eschar produced by the nitric acid separated, it left a weakly looking surface, which, in a few days how: ever, improved, as did also the general hewlth and the condition of the arm; the corded lymphatics having almom disappeared. But this was only a temporary change; the sore again became painful, and acquired its suspicious look, with whitish surface, red and sharp cut edge; moreover, it was now raised on a hardened base; the lymphatic cords on the forearm became very manifest; one of the axillary glands enlarged; and seven weeks from the origin of the sore, a well marked copper coloured roseola made its appearance on the palms of the hands and trunk. The problem was now solved, and the moment for decided action arrived. I destroyed the primary sore with strong nitric acid,* and commenced a mild course of mercurial treatment. After the lapse of another week, the skin affection had quite disappeared, the affection of the lymphatics almost so, and the sore had quite healed; but a good deal of induration remained at its base, and pathognomic sores formed on both tonsils. Both these complications slowly but progressively yielded to corrosive sublinnate and sarsaparilla, followed by iodide of potassium.

REMARKS. The study of this casc suggests two facts for special consideration-the failure of the inoculation, and the error in not diagnosing the primary sore from its history and anatomical characters.

Were it not that the surgeon who performed the inoculation has frequently practised it successfully, the validity of the experiment might be questioned ; but under present circumstances, the failure tends to lessen the value of inoculation, as a means of ascertaining the syphilitic character of a suspicious sore. But it is just to observe that almost invariably, the inoculation of the discharge from a primary venereal surface, does produce a chancre. Indeed, amongst a very large number of experimental inoculations of undoubted chancrous pus, I have only seen one failure besides my own case. That occurred in a young man, the subject of chronic phthisis; he had had a chancre at the franum for about three weeks, and it had destroyed a considerable portion of the glans. I performed three inoculations on the same patient with pus from the surface of the sore; they all failed. The primary sore healed after being twice cauterised with nitric acid. Any doubt as to its true syphilitic nature, was removed by the appearance in little more than another fortnight of syphilitic ecthyma in its most severe form.

Apart from experimental inoculation, there were, I now think, sufficient grounds for diagnosing the sore as syphilitic. The idea of $\mathrm{my}$ friends, that it was a common sore due to impairment of the general health by hospital work, had no better foundation than their kind hope that it should prove to be such ; for it had none of the appearance, either at its commencement or during its progress, of the weakly sores that occasionally form abuut the pulps of the fingers and roots of the nails in weakly constitutions. Its bright red sharply cut edge, the white adherent slough on the surface, the burning pain, corded state of the lymphatics, the hardened base, conjoined with the fact that, just before its appearance, I had exposed myself to the risk of inoculating the thumb; that the general health was excellent; that when it failed, rest, fresh air, change of scene, and exercise, resorted to for its improvement, had no effect on the sore-appear to have been sufficient grounds for the

* I have bren in the habit of riving phloroform in rauterising chancres; but my experience in this case, conjoined with the ruther mumeroms accident from this ausesthetie of late recordecl, which sughest the propriety of only resoltiug to it when renlly neccsirs, and then with the greatest precaution, lends me to cuestion whether in many of these coses lle preventive is not as screre as the , gin. Certain it. i-, thit I sufti-red greatly from the chloroform for nearly thirty-six hours afterwards-ercat prostrution, headache, and vo mitiug. iut when, having determince upon the necessity of reaphlying the nitric acid, 1, in lie absence of a frieud, in a village on the binks of the Thone, applied it myself, the pain wus severe, it is true, but ceased in a fer miuntes; und whereas I had not rested for many nights, I fell off to sleep half au hour afterwards slept soundly ten hours, and was enabled to resume my journey in comparative ease. 
diagnosis. Repeated cauterisation until the specific character of the sore was destroyed, and a mild mercurial course, would have been prudent precautionary measures; at least, they would not have been productive of mischief.

Paluzzo Corsi, Florence, Nuv. 2th, l×b3.

\section{BIBLIOGRAPHICAL NOTICES.}

Menorrs of Joun Abersetiry, F.R S.: with a View of his Lectures, Writings, and Character. By George MacILWAIs, F.R.C.S. 2 vols. 8vo., pp. 334 and 370. London: $18 \% 3$.

Trus is an entertaining work; but we should have been better pleased with it, had it told us more than it does about its professed sulject. We are not at all certain that the author is to blame for the mearreness of his details; but thequestion arises, - W is it necessary to expand his scanty materials into two octavo volumes by sparse printing, and the incorporation of foreign matter? We think that this might have been judiciously avoided. Perhaps, however, many readers may appreciate the work all the more, that it gives a narrative of some striking passages in the history of the pupil and biographer, as well as his sharp and free criticisms upon the abuses of the hospital system in London, and other real or supposed benishes in the medical polity of the present day. For our own part, while, as critics, we are bound to condemn the discursive character of these volumes, and find fault with the attempt to give, in the form of a biography, matter wholly unsuitalble to the legitimate plan of such a work, we must admit that the author is generally lively, earnest, and instructive. Nevertheless, as a biography, the book has not been correctly conceived. Complete success in biographical writing can only be attained by griving a narrative in which the hero is carefully kept in the foreground, and in which he is never veiled cr removed fom the reader by the interposition of the writer, or of any other monopolising person or thing.

Joln A menxwiny was born in Coleman Street, London, on the 3rd of April, 1764, or 1765. He was the second son of John Abernethy, a merchant, who traded under the firm of Ahernethy and Donaldson, in Rood Lane, Fenchurch Street. The culture of his childhood was conducted at home; but, at an early age, he was sent to the grammar school of Wolverhampton, where he received the principal part of his elucation. He had a predilection for the bar; lut, in 1779 , his father apprenticed him to Sir Charles Blicke, a surgeon in large and lucrative practice, who then resided in Mildred's Court. Speaking of his apprenticeship, Mr. Macilwain remarks:-

"J)iligent as he was, we suspect he found little during his apprenticeship, of thoce attractions which make lahour and industry sources of pleaniure and enjoyment. As a matter of course he would have been allowed to attend any lectures which were given at, the hospital to which Sir Charles Blicke was surgeon, (St. lartholnmew's), and they would bring him in contact with Mr. P'ott, who delivered a rertain number of surgical lectures there. There were no courses of anatomical lectures given at St. liartholome'w's at that period ; but anatomical lecturis wore dilivered resularly at the Iondon Hospital, by I). Narlaurin and Sir William lilizard, and afterwards hy sir Willian Blizard alone. As Sir C. Blicke lived in Mildred's Court and suliserpently in Billeter Square, Alernethy would be about equidivtaut from the two hespitals, both of which he attended. We incline to think that it was in attending the lectures, and perhaps especially those of sir William Blizard, that he first foumd thos awakening impulses which excited in him a real love for hic protession. It was about this time, we think, that lee biran to have more enlarged ideas of the nature and olijects of surcical seience; a state of mind calculated to enalle him to thoroughls understand and appreciate Nr. Hunter, and to deduce from the principles which he was shadowing forth those relations and consenuences which we shall endeavour popularly to explain : principles which, though originally direrted to the treatment of so-called surgical malalies, were found equally to affect the practice of medicine." (vol. $i, p .45-\tau$.)

At the London Hospital, Abernethy was in the habit of preparing the subjects for lecture, which fitted him to enter upon the duties of a teacher at St. Bartholomew's with advantage, when that field was opened to him by the resignstion of Mr. Pott as surgeon to that hospital. Sir Charles Blicke, assistant-surgeon, succeeded to Mr. Pott's position; and the vacancy created by the promotion of Sir Charles was filled up, on the 15th of July, 1787, by the appointment of Abernethy. The election was contested by several candidates: at last, it lay between Mr. Jones and Abernethy, when the former polled twenty-nine, and the latter fifty-three votes.

"As assistant-surgeon he had no emolument from the hospital: he had therefore a very reasonable inducement to set abont doing that for which he felt himself calculated, and to which he had early directed his attention-nanely, to teach his profession. The event showed that he had by no means miscalculated his powers. These proved well-uigh unrivalled. The appointment to St. Bartholomew's, besides other advantages ave him an opportunity of lecturing with the prestige usually affioded by connection with a large hospital. He did not, however, give lectures at the hospital at first, but delivered them in Bartholomew Close. 'There was at this time, in fact, no school, properly socalled, at st. liartholomew's. Nr. Pott gave ubout twenty-four lectures, which as short practical discourses, were first rate for that period. IBut there were no other lectures, not even on anatomy, which are essentially the basis of a medical school.

“ 1)r. Marshall, who was a very remarbable unan, and no less eminent. for his generul ability than for his professional acquirements, at this time wns giving anatomical lectures at his house in Bartlett's Buildings, Holliorn. In a liographical notice of him in the Gentleman's Majjazine, in which we read that he was riving lectures about the vear 1787 , it is incidentally remarked that "in all proluability he derived little sul port from st. Tartholomew's Hospital ; for recently, an ingenions young gentleman, $\mathrm{ll}_{\mathrm{r}}$. Alienethy, had begun to give lectures in that neighbourhood. Aleernethy, who seems to have been always seling information, certainly attended some of Mar shall's lectures; becanse he would oceasionally ref $r$ to anecdotes he had heard there. Ho had thus attended most of the best lecturers of his day,-sir W. Blizard, 1)r. Maclaurin, Mr. Pott, and Mr. Marshall." (rol. i, p. be-6s.)

It would appear that Abernethy lectured with acceptance on anatomy, physiology, pathology, and surgery, notwithstanding an unconquerable "shyness". This shyness we find traces of in various parts of his life; and there seems to be no doult of its having existed, however difficult it may be to reconcile it with that self-confidence and rude behaviour before patients for which $\Lambda$ bernethy deservedly acyuired a reputation: and to this, we may add, he owed some of his success. Abernethy's lectures became so popular, that it was at last necessary to provide better accommodation for his pupils.

"The governors of the hospital in 1790 determined on building a regular theatre within the liuspital. It was finished in 17!)l; and Alermethy gave his October courses of anatomy, physiology, and surgery of that year in the new theatre. He hail thus become the founder of the school of St. Bartholomew's, which for the approaclies it made towards giving a more scientilic plase to the practice of surgery, was certainly superior to any other. In expressing this opinion, we of course except John Hunter's lectures fi.r the short time that they were contemporaneous with linose of Mr. Abernethy; John Hunter dying in 17!):" (vol. i, p. is.)

After describing Abernethy's attainment of distinction and popularity as a lecturer, Mr. Macilwain enlarges upon the varied scientific pursuits in which he engaged. His Essay on Lumbur $A$ liscess is deservedly praised; but we cannot think that $\Lambda$ bernethy's treatment of cases of this description is so much "misunderstood" as his biographer supposes; but, even if it were so, we do not think that the proper method of removing this misunderstanding is by the introduction of a discussion regarding it in a work avowedly written for the general public. To enlighten the profession through pojular works is to run the risk of being charged with an undue disparagement of the knowledge of our colleagues or competitors. Perhaps Mr. Macilwain has had the conduct of Abernethy too favourably before him when 